\title{
Pengembangan Game Jegog Berbasis Android
}

\author{
I Gede Wija Antara ${ }^{1}$, I Gede Mahendra Darmawiguna ${ }^{2}$, I Made Gede Sunarya ${ }^{3}$ \\ Jurusan Pendidikan Teknik Informatika \\ Universitas Pendidikan Ganesha \\ Singaraja, Bali \\ E-mail:wija.antara@gmail.com ${ }^{1}$, igd.mahendra.d@gmail.com ${ }^{2}$, imadegedesunarya@gmail.com ${ }^{3}$
}

\begin{abstract}
Abstrak- Gamelan Jegog merupakan salah satu perangkat gamelan Bali yang bilah-bilahnya terbuat dari bambu. Tiap-tiap tungguh instrumen yang membangun perangkat Jegog itu sendiri terdiri dari delapan bilah dan dimainkan dengan dua buah panggul baik terbuat dari kayu maupun karet. Game Jegog Berbasis Android merupakan aplikasi yang mengadaptasikan Jegog yang merupakan alat musik tradisional ke dalam sebuah game yang dijalankan pada platform Android. Penelitian ini bertujuan untuk merancang dan mengimplementasikan rancangan aplikasi Game Jegog Berbasis Android.
\end{abstract}

Pengembangan Game Jegog Berbasis Android menggunakan siklus hidup pengembangan perangkat lunak dalam bentuk sekuensial linier atau model air terjun. Fitur utama dari aplikasi ini adalah permainan Jegog (Game Mode) untuk mendapatkan skor tertinggi. Terdapat juga fitur lainnya yaitu berlatih untuk memainkan Jegog (Learn Mode) sesuai dengan tabuh yang tersedia dan memainkan Jegog secara bebas ( Free Mode ).

Hasil dari penelitian ini yaitu perancangan dan implementasi Game Jegog Berbasis Android telah berhasil dilakukan. Perancangan dilakukan dengan menggunakan model fungsional berupa UML (Unified Modeling Languange). Diimplementasikan dalam bahasa pemrograman Java dengan menggunakan editor Eclipse dan plugins ADT (Android Development Tools) serta menggunakan AndEngine sebagai library tambahan. Seluruh kebutuhan fungsional telah berhasil diimplementasikan sesuai dengan rancangan.

Kata Kunci : Jegog, game, Android

Abstract - Gamelan Jegog is one of the traditional instrument which originally comes from Bali. Each Jegog's instrument consists of eight piece of bamboo with each piece is called as "bilah". Jegog is played with two "panggul". "Panggul" is a tool used for hitting the instrument and is usually made of wood or rubber. Game Jegog berbasis Android was an application that adapts Jegog into a game that run on the Android platform. This research aimed at designing and implementing Jegog based Android Game.

Game Jegog Berbasis Android was developed by the Software Development Life Cycle (SDLC) in the form of sequential linear or waterfall model. The main feature of this application was Jegog game (Game Mode) to attain the highest score. There were also other features such as playing Jegog with melody (Learn Mode) and playing Jegog freely (Free Mode).

The results of this research were the design and the implementation of Game Jegog berbasis Android. The game was designed through UML (Unified Modeling Language). It was implemented in Java programming language by using the Eclipse editor and ADT (Android Development Tools) plug ins. It also used AndEngine as additional library. The entire functional requirements had been successfully implemented in accordance with the design.

Keyword : Jegog, game, Android

\section{PENDAHULUAN}

Pulau Bali atau yang sering disebut pulau dewata merupakan pulau yang terkenal hingga penghujung dunia. Salah satu faktor yang menyebabkan Bali terkenal hingga ke penghujung dunia adalah budaya yang dimilikinya. Kebudayaan berarti keseluruhan gagasan dan karya manusia yang harus dibiasakan dengan belajar serta keseluruhan dari hasil budi pekertinya [1]. Ada tujuh unsur dalam kebudayaan universal yaitu sistem religi dan upacara keagamaan, sistem organisasi kemasyarakatan, sistem pengetahuan, sistem mata pencaharian hidup, sistem teknologi dan peralatan, bahasa, serta kesenian [1]. Kesenian sebagai salah satu dari tujuh unsur kebudayaan terdiri dari bidang seni pahat, seni gamelan, seni lukis, seni tari, seni hias, seni patung.

Gamelan Jegog merupakan salah satu seni gamelan yang ada di Indonesia khususnya di Bali. Gamelan Jegog merupakan salah satu perangkat gamelan Bali yang bilah-bilahnya terbuat dari bambu. Tiap-tiap tungguh instrumen yang membangun perangkat Jegog itu sendiri terdiri dari delapan bilah dan dimainkan dengan dua buah panggul baik terbuat dari kayu maupun karet [2].

Permasalahan yang terjadi di masyarakat yang berkaitan dengan Jegog yaitu Jegog masih 
belum banyak dikenal oleh masyarakat dan seniman Bali yang berasal dari kabupatenkabupaten lain di Bali. Hal tersebut disebabkan oleh penyebaran Jegog hanya di Bali Barat khususnya Kabupaten Jembrana saja. Selain itu, permasalahan yang terjadi di masyarakat adalah kurangnya minat masyarakat untuk memainkan Jegog yang merupakan alat musik tradisional. Faktor yang menyebabkannya adalah masuknya berbagai kebudayaan luar dengan segala modernisasinya sehingga budaya tradisional dalam hai ini alat musik tradisional terkesan menjadi kuno, serta harga satu set instrumen Jegog terbilang mahal sehingga tidak semua masyarakat memiliki Jegog.

Solusi yang peneliti usulkan berdasarkan permasalahan di atas adalah dengan mengembangkan sebuah aplikasi permainan Jegog yang dikembangkan pada sistem operasi Android dengan nama Game Jegog Berbasis Android. Aplikasi dikembangkan pada sistem operasi Android karena Android banyak digunakan oleh masyarakat dan memiliki beberapa kelebihan seperti harga terbilang terjangkau, mampu digunakan di berbagai segmen, mulai dari kalangan menengah, bawah, maupun eksekutif muda dan fiturnya yang lengkap selalu update. Dengan dikembangkannya aplikasi ini, diharapkan akan dapat membuat Jegog lebih dikenal oleh masyarakat luas dan masyarakat Bali pada khsusnya serta masyarakat dapat memainkan Jegog tanpa harus membeli alat musik Jegog yang harganya terbilang mahal.

\section{KAJIAN TEORI}

A. Jegog

Gamelan Jegog merupakan alat musik tradisional khas yang berasal dari Kabupaten Jembrana dimana Jegog ditemukan oleh I Wayan Geliduh pada tahun 1912. Gamelan Jegog merupakan salah satu perangkat gamelan Bali yang bilah-bilahnya terbuat dari bambu. Tiap-tiap tungguh instrumen yang membangun perangkat Jegog itu sendiri terdiri dari delapan bilah dan dimainkan dengan dua buah panggul baik terbuat dari kayu maupun karet [2].

\section{B. Game}

Kata game berasal dari bahasa Inggris yang berarti permainan. Permainan adalah sesuatu yang digunakan untuk bermain yang dimainkan dengan aturan-aturan tertentu. Game adalah permainan yang menggunakan media elektronik, merupakan sebuah hiburan berbentuk multimedia yang dibuat semenarik mungkin agar pemain bisa mendapatkan sesuatu sehingga adanya kepuasaan batin [3].

\section{Android}

Android adalah sebuah sistem operasi (OS) yang bersifat Open Source (terbuka) yang dimiliki oleh Google.Inc. Pada awal peluncurannya, Android hanya digunakan untuk perangkat mobile, yaitu telepon seluler. Namun seiring perkembangannya, sejak Android 3.0 (Honeycomb) diluncurkan, sistem operasi Android resmi digunakan dalam komputer tablet. Android memiliki banyak kelebihan, tidak hanya dari segi harga yang terbilang terjangkau, namun juga mampu digunakan di berbagai segmen, mulai dari kalangan menengah, bawah, maupun eksekutif muda. Android bisa dikatakan jawaban dari keberagaman masyarakat perkotaan, mengingat mereka mempunyai berbagai kebutuhan dan pekerjaan yang harus dilakukan dalam waktu yang bersamaan. Berkat fitur yang selalu update, keberadaan Android mencuri perhatian penggunanya. Oleh sebab itu, pertumbuhannya dari tahun ke tahun dapat terlihat secara signifikan [4].

\section{Eclipse}

Eclipse adalah sebuah IDE (Integrated Development Environment) untuk mengembangkan perangkat lunak dan dapat dijalankan di semua platform (platformindependent). Eclipse pada saat ini merupakan salah satu IDE favorit dikarenakan gratis dan open source. Kelebihan dari Eclipse yang membuatnya populer fasilitas plug-in yang dimilikinya, dengan menggunakan plug-in membuat Eclipse dapat digunakan untuk mengembangkan pemrograman selain Java untuk berbagai bermacam keperluan. Pengembangan aplikasi Android menggunakan Eclips, menggunakan bahasa Java dan plug-in Android Development Tools (ADT). Aplikasi Android yang telah dibuat di Eclipse dapat dijalankan menggunakan AVD (Android Virtual Device), sehingga kita tidak harus memerlukan perangkat Android asli [5].

\section{E. AndEngine}

AndEngine merupakan game engine yang memfokuskan pada pembuatan game berbasis 2D di platform Android. Karena sudah berupa engine maka pembuat game akan dipermudah dengan disediakan banyak fitur-fitur untuk membuat game. Berikut beberapa fitur yang disediakan oleh AndEngine seperti resolusi, landscape/potrait, sprite, animasi, pengecekan tubrukan (collision) 
texture, font, event touch dan accelerometer, particle dan lain-lain [6].

\section{METODOLOGI}

\section{A. Analisis Masalah dan Usulan Solusi}

Berdasarkan analisis yang peneliti lakukan, terdapat permasalahan yang terjadi di masyarakat yang berkaitan dengan Jegog yaitu Jegog masih belum banyak dikenal oleh masyarakat dan seniman Bali yang berasal dari kabupatenkabupaten lain di Bali. Hal tersebut disebabkan oleh penyebaran Jegog hanya di Bali Barat khususnya Kabupaten Jembrana saja. Selain itu, permasalahan yang terjadi di masyarakat adalah kurangnya minat masyarakat untuk memainkan Jegog yang merupakan alat musik tradisional. Faktor yang menyebabkannya adalah masuknya berbagai kebudayaan luar dengan segala modernisasinya sehingga budaya tradisional dalam hai ini alat musik tradisional terkesan menjadi kuno. Selain itu, harga satu set instrumen Jegog terbilang mahal sehingga tidak semua masyarakat memiliki Jegog.

Solusi yang peneliti usulkan berdasarkan permasalahan di atas adalah dengan mengembangkan sebuah aplikasi permainan Jegog yang dikembangkan pada sistem operasi Android dengan nama Game Jegog Berbasis Android. Dengan dikembangkannya aplikasi ini, diharapkan akan dapat membuat Jegog lebih dikenal oleh masyarakat luas dan masyarakat Bali pada khsusnya serta masyarakat dapat memainkan Jegog tanpa harus membeli alat musik Jegog yang harganya terbilang mahal.

B. Analisis Perangkat Lunak

1. Kebutuhan Perangkat Lunak

Game Jegog Berbasis Android dirancang agar dapat mengimplementasikan kebutuhan fungsional sebagai berikut.

a. Menampilkan Main Menu yang terdiri dari Play Game, Learn To Play, Settings, Help, dan About.

b. Menampilkan antarmuka Free Mode dan Learn Mode.

c. Menampilkan antarmuka Game Mode.

d. Menampilkan skor saat permainan selesai.

e. Memiliki fitur pengaturan.

f. Menampilkan skor tertinggi.

g. Menampilkan bantuan.

h. Menampilkan tentang pengembang aplikasi.

Adapun kebutuhan non-fungsional dari aplikasi yang dikembangkan yaitu aplikasi dibuat agar user friendly bagi pengguna sehingga pengguna mudah untuk menggunakan aplikasi.

2. Tujuan Pengembangan Perangkat Lunak Adapun tujuan pengembangan perangkat lunak adalah sebagai berikut.

a. Aplikasi dapat menampilkan Main Menu yang terdiri dari Play Game, Learn To Play, Settings, Help, dan About.

b. Aplikasi dapat menampilkan antarmuka Free Mode dan Learn Mode.

c. Aplikasi dapat menampilkan antarmuka Game Mode.

d. Aplikasi dapat menampilkan skor saat permainan selesai.

e. Aplikasi menyediakan fitur pengaturan.

f. Aplikasi dapat menampilkan skor tertinggi.

g. Aplikasi dapat menampilkan bantuan.

h. Aplikasi dapat menampilkan tentang pengembang aplikasi.

\section{Masukan dan Keluaran Perangkat Lunak}

Masukan (input) pada Game Jegog Berbasis Android adalah berupa sentuhan (touch) pada layar saat bermain game atau berlatih, sedangkan keluaran (output) dari Game Jegog Berbasis Android adalah suara dari aplikasi.

\section{Model Fungsional Perangkat Lunak}

Dalam pengembangan aplikasi ini, peneliti menggunakan dua macam diagram yaitu use-case diagram dan activity diagram.

a. Use Case Diagram

Use case diagram menggambarkan fungsionalitas yang diharapkan dari sebuah sistem. Seorang/sebuah aktor adalah sebuah entitas manusia atau mesin yang berinteraksi dengan sistem untuk melakukan pekerjaanpekerjaan tertentu [7].

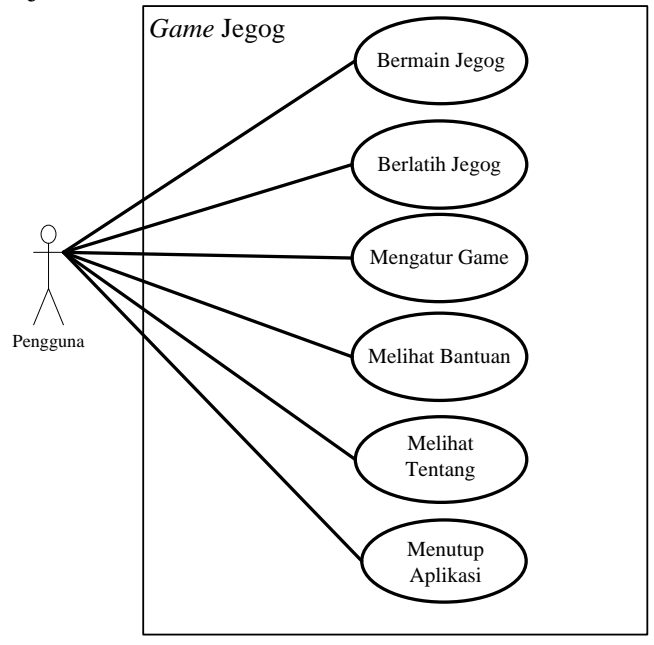




\section{ISSN 2087-2658 \\ Jurnal Nasional Pendidikan Teknik Informatika (JANAPATI) \\ Volume 4, Nomor 2, Juli 2015}

Gambar 1. Use Case Diagram

\section{b. Activity Diagram}

Activity diagram menggambarkan berbagai alir aktivitas dalam sistem yang sedang dirancang, bagaimana masing-masing alir berawal, decision yang mungkin terjadi, dan bagaimana mereka berakhir. Activity diagram juga dapat menggambarkan proses parallel yang mungkin terjadi pada beberapa eksekusi [7].

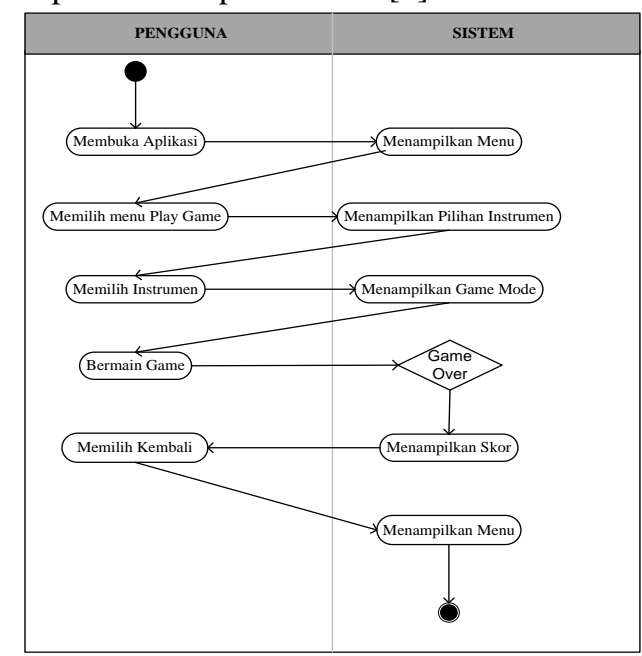

Gambar 2. Activity Diagram Bermain Jegog

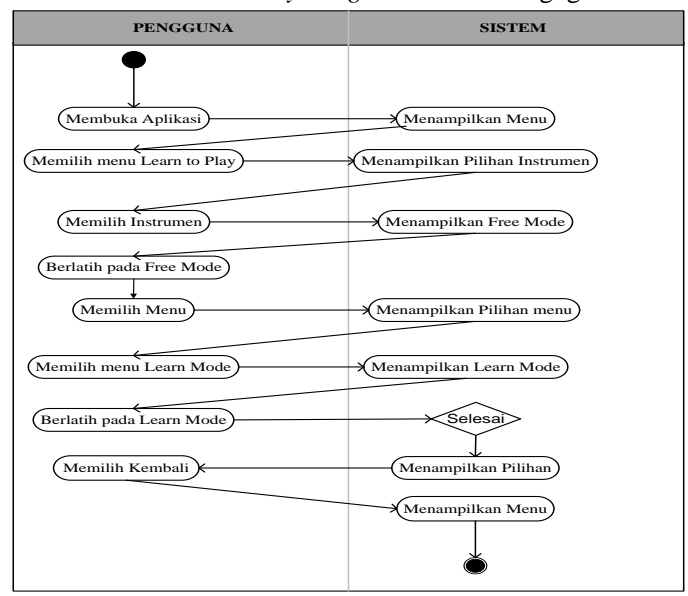

Gambar 3. Activity Diagram Berlatih Jegog

C. Perancangan Perangkat Lunak

1. Batasan Perancangan Perangkat Lunak

Adapun batasan perancangan dalam

pengembangan aplikasi ini yaitu:

a. Pemain tidak dapat menambahkan tabuh ke dalam game.

b. Game Jegog Berbasis Android merupakan game offline.

2. Perancangan Arsitektur Perangkat Lunak

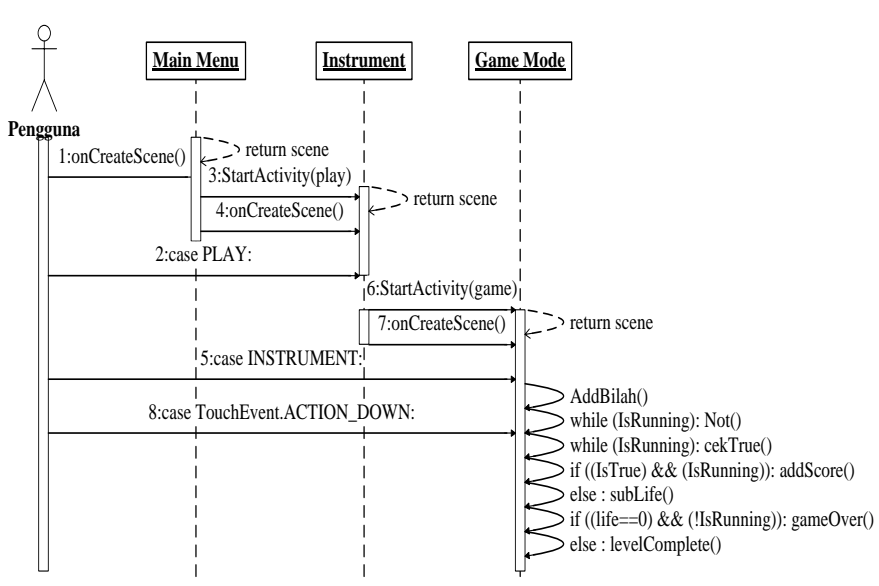

Gambar 4. Perancangan Arsitektur Perangkat Lunak

3. Perancangan Skenario Game

Perancangan skenario game dari aplikasi ini adalah sebagai berikut.

a. Sebelum memulai game, pemain memilih instrumen yang akan dimainkan.

b. Pada awal permainan, pemain memiliki toleransi kesalahan (life). Toleransi kesalahan disesuaikan dengan tingkat kesulitan, untuk tingkat kesulitan easy memiliki toleransi kesalahan 50, untuk tingkat kesulitan normal memiliki toleransi kesalahan 30, untuk tingkat kesulitan hard memiliki toleransi kesalahan 15.

c. Terdapat 6 level dengan kesulitan yang terus meningkat dari level 1 sampai level 6 . Kesulitan yang dimaksud baik dari segi kesulitan tabuh.

d. Saat mulai permainan akan diberikan tanda "Go !".

e. Game dimainkan dengan menekan tomboltombol yang muncul pada layar sesuai dengan tabuh pada area yang telah ditentukan.

f. Pada saat tertentu akan muncul tombol yang dapat berupa bonus atau perangkap.

g. Apabila tabuh pada level tertentu sudah selesai, maka game akan menuju ke level selanjutnya dengan tabuh yang berbeda.

h. Apabila terjadi miss atau pemain tidak berhasil menekan tombol tepat waktu, maka toleransi kesalahan akan dikurangi 1.

i. Game akan berakhir jika permainan sudah melewati level 6 atau toleransi kesalahan sudah habis.

j. Di akhir permainan akan diberikan total skor sesuai jumlah tombol yang berhasil ditekan oleh pemain. Skor untuk masing masing tombol bervariasi, disesuaikan dengan tingkat kesulitan dan level permainan. 
4. Perancangan Struktur Navigasi

Struktur navigasi merupakan struktur atau alur dari suatu program. Struktur navigasi juga memberikan kemudahan dalam menganalisa keinteraktifan seluruh objek dalam aplikasi dan bagaimana pengaruh keinteraktifannya terhadap pengguna [8].

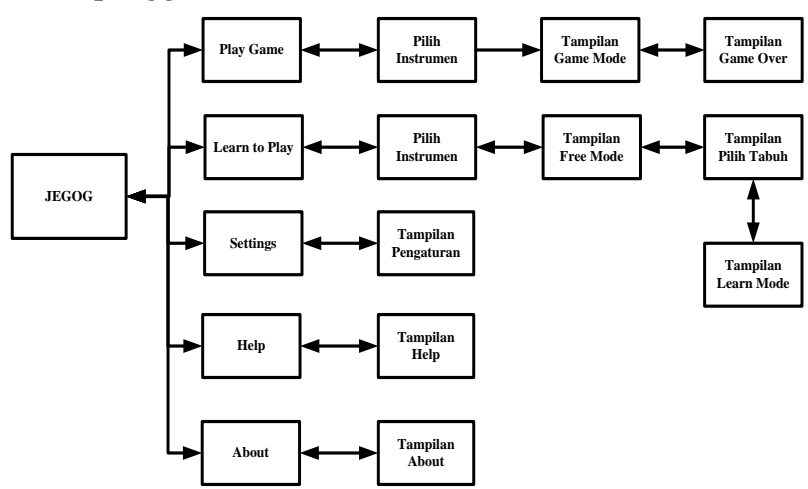

Gambar 5. Struktur Navigasi Perangkat Lunak

5. Perancangan Antarmuka Perangkat Lunak

Perancangan antarmuka perangkat lunak merupakan proses pembuatan antarmuka yang akan digunakan untuk berinteraksi antara pengguna dengan perangkat lunak. Rancangan antarmuka yang dibuat user friendly agar pengguna tidak mengalami kesulitan dalam menggunakan aplikasi.

a. Perancangan Antarmuka Main Menu

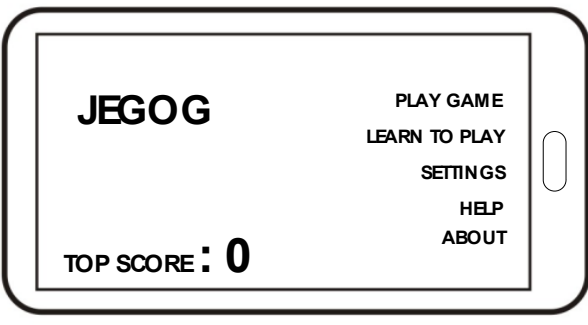

Gambar 6. Rancangan Antarmuka Main Menu

b. Perancangan Antarmuka Instrument

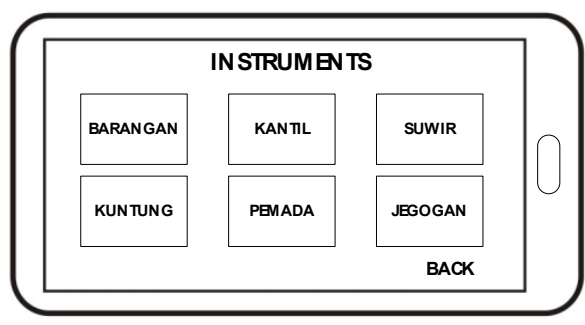

Gambar 7. Rancangan Antarmuka Instrument

c. Perancangan Antarmuka Game Mode

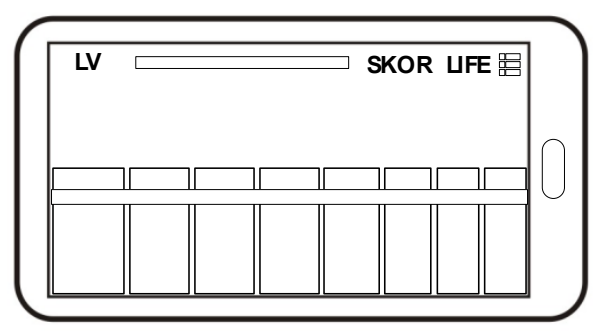

Gambar 8. Rancangan Antarmuka Game Mode

d. Perancangan Antarmuka Free Mode

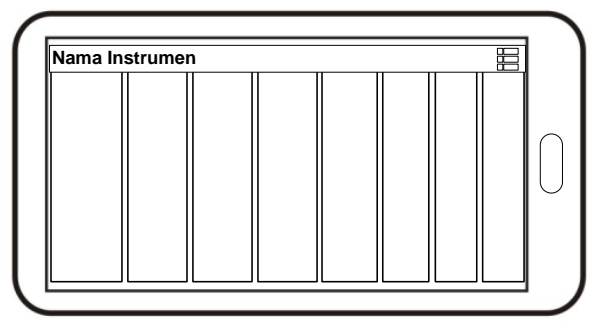

Gambar 9. Rancangan Antarmuka Free Mode

e. Perancangan Antarmuka Learn Mode

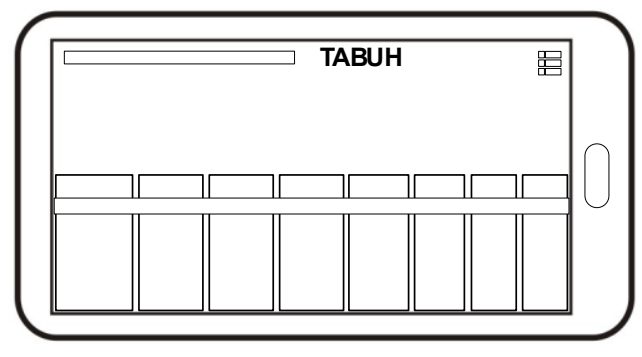

Gambar 10. Rancangan Antarmuka Learn Mode

f. Perancangan Antarmuka Settings

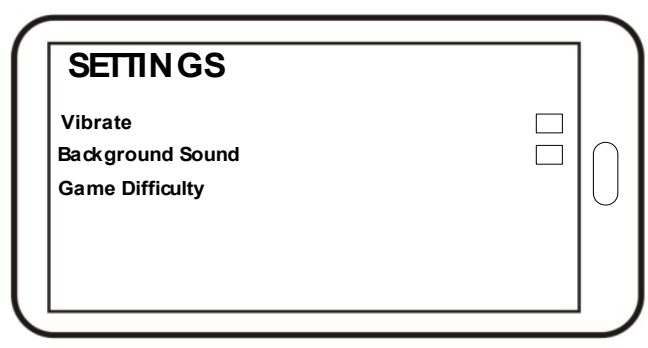

Gambar 11. Rancangan Antarmuka Settings

g. Perancangan Antarmuka Help 


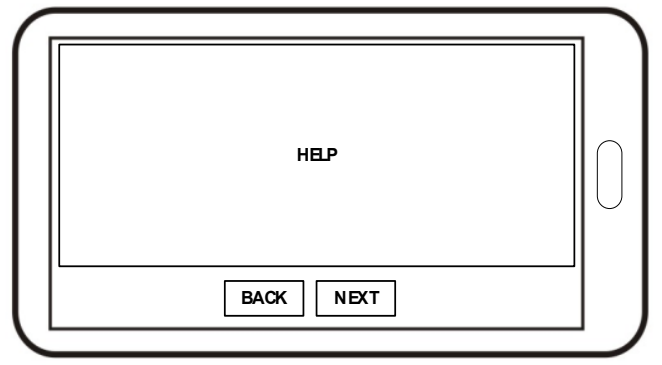

Gambar 12. Rancangan Antarmuka Help

h. Perancangan Antarmuka About

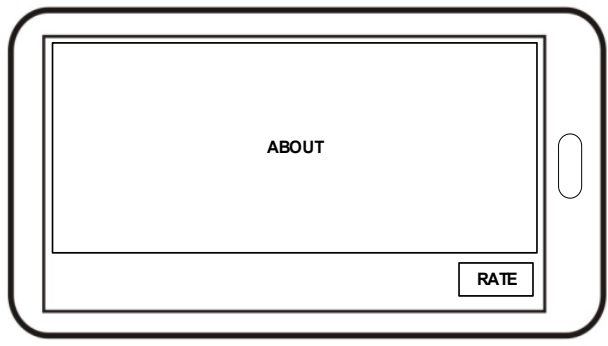

Gambar 13. Rancangan Antarmuka About

\section{IV.PEMBAHASAN}

A. Implementasi Perangkat Lunak

1. Lingkungan Implementasi Perangkat Lunak Implementasi Game Jegog Berbasis Android dilakukan pada lingkungan perangkat lunak yaitu : Eclipse, Plugins ADT (Android Development Tools), AndEngine GLES2, Adobe Photoshop CS 4, dan Audacity.

Adapun lingkungan perangkat kerasnya yaitu sebuah laptop dengan spesifikasi seperti monitor 14,1 inchi, memori 4 GB RAM, harddisk $500 \mathrm{~GB}$, processor Intel ${ }^{\circledR}$ Core $^{\mathrm{TM}}$ i3 $2.4 \mathrm{Ghz}$.

Perangkat keras lainnya yaitu sebuah perangkat Android dengan spesifikasi seperti Android 4.1.2 (Jelly Bean), layar 7 inchi (1024 x 600), RAM 1 GB, Processor ARM Cortex-A9 1,2 Ghz, dan GPU GC1000 core.

2. Batasan Implementasi Perangkat Lunak

a. Spesifikasi perangkat minimal yang diperlukan untuk menjalankan aplikasi yaitu Processor ARM-v7a, GPU kelas mid-end, RAM 512 MB, OS Android versi 2.3 (Gingerbread), dan resolusi layar 320 x 480.

b. Suara dan musik yang dari aplikasi akan berbeda antara menggunakan speaker perangkat Android dengan menggunakan speaker atau earphone tambahan

c. Pemain tidak bisa menambahkan tabuh ke dalam game.

d. Game Jegog Berbasis Android merupakan game offline.

3. Implementasi Antarmuka Perangkat Lunak Implementasi antarmuka dilakukan sesuai dengan rancangan antarmuka yang telah dibuat sebelumnya.

a. Implementasi Antarmuka Main Menu

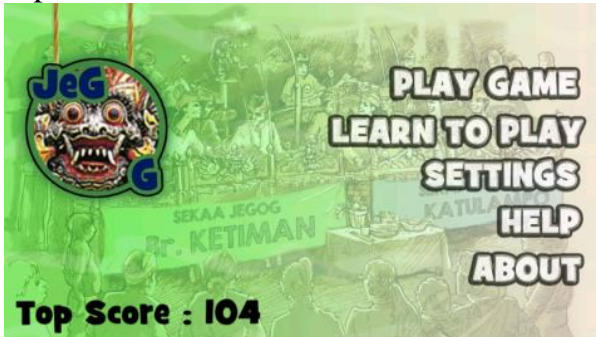

Gambar 14. Implementasi Antarmuka Main Menu

b. Implemenasi Antarmuka Instrument

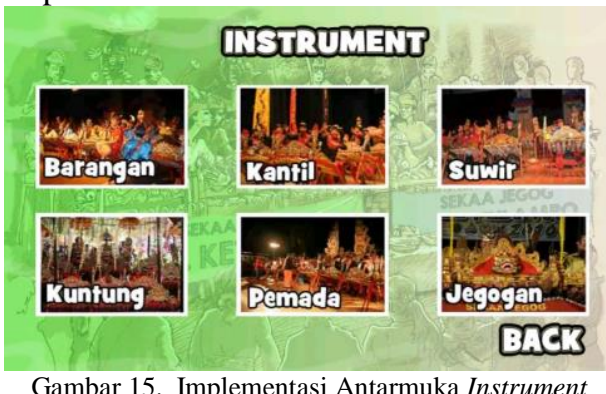

c. Implemenasi Antarmuka Game Mode

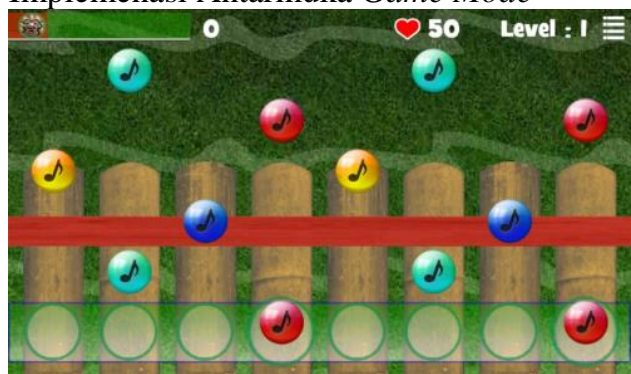

Gambar 16. Implementasi Antarmuka Game Mode

d. Implemenasi Antarmuka Free Mode 


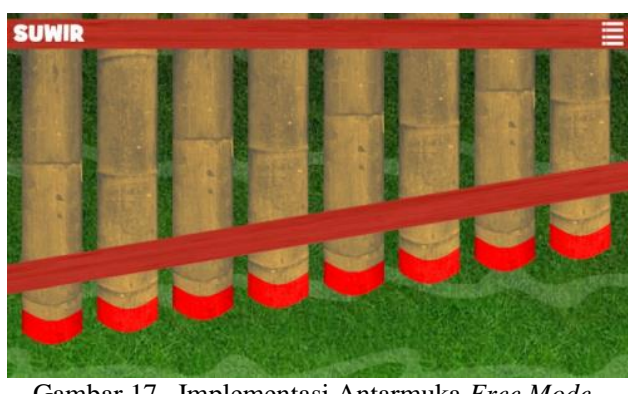

Gambar 17. Implementasi Antarmuka Free Mode

e. Implemenasi Antarmuka Learn Mode

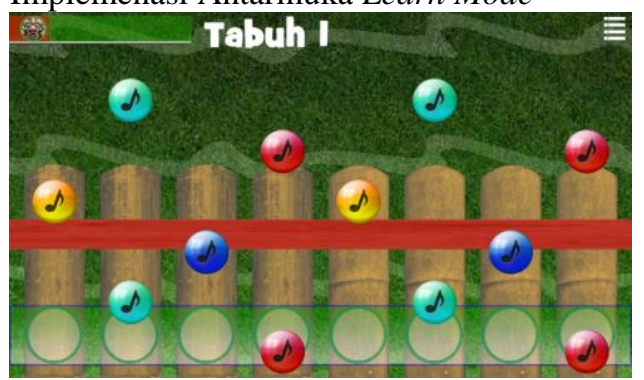

Gambar 18. Implementasi Antarmuka Learn Mode

f. Implemenasi Antarmuka Settings

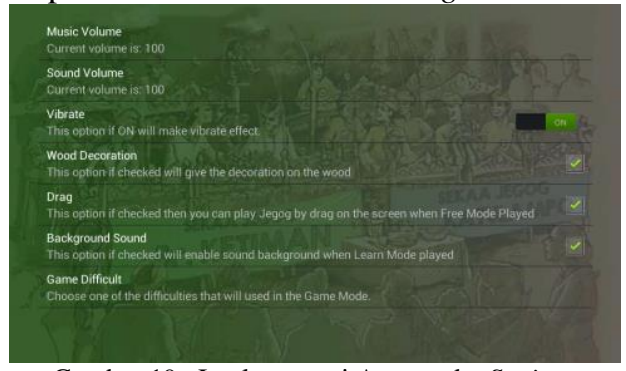

Gambar 19. Implementasi Antarmuka Settings

g. Implemenasi Antarmuka Help

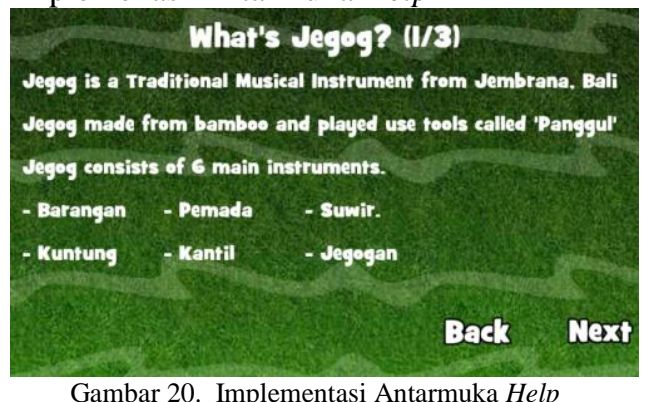

h. Implementasi Antarmuka About

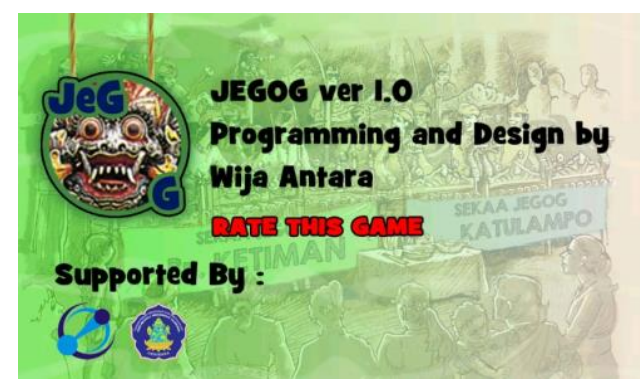

Gambar 21. Implementasi Antarmuka Help

B. Pengujian Perangkat Lunak

1. Tujuan Pengujian Perangkat Lunak

Tujuan pengujian aplikasi Game Jegog Berbasis Android, yaitu:

a. Menguji penggunaan aplikasi perangkat Android yang berbeda

b. Menguji kebenaran proses aplikasi

c. Menguji kualitas suara dan musik yang dihasilkan aplikasi dengan speaker perangkat Android

d. Menguji kualitas suara dan musik yang dihasilkan aplikasi dengan speakerlearphone tambahan.

2. Perancangan Kasus Uji Pengujian Perangkat Lunak

Pada tahap ini dideskripsikan secara mendetail bentuk bentuk uji kasus yang akan dilaksanakan sesuai dengan tujuan pengujian dan tata ancang pengujian yang telah ditetapkan. Uji kasus yang dibuat selengkap mungkin agar hasil pengujian lebih valid. Terdapat empat kasus uji yang dirancang sesuai dengan tujuan pengujian perangkat lunak yang digambarkan dengan angket pengujian.

3. Pelaksanaan Pengujian Perangkat Lunak

Pengujian perangkat lunak Game Jegog Berbasis Android dilakukan pada beberapa perangkat android dengan merk dan spesifikasi yang berbeda. Pengujian pada beberapa perangkat yang berbeda bertujuan untuk mengetahui performa dan kompabilitas dari masing-masing perangkat dalam menjalankan aplikasi Game Jegog Berbasis Android. Pengujian dilakukan sesuai dengan tata ancang dan teknik pengujian perangkat lunak dengan menggunakan angket yang telah dirancang. Pengujian dilaksanakan pada Sabtu, 19 April 2014 dengan penguji yaitu mahasiswa Jurusan Pendidikan Teknik Informatika yang berjumlah 10 orang dan 
bertempat di gedung Fakultas Teknik dan Kejuruan.

4. Evaluasi Hasil Pengujian Perangkat Lunak

Berdasarkan pengujian yang telah dilakukan, Game Jegog Berbasis Android dapat dijalankan pada semua perangkat Android yang diujikan sesuai dengan kebutuhan minimum aplikasi yang telah ditetapkan. Pengujian dilakukan dengan menggunakan beberapa merk perangkat Android diantaranya Samsung, Sony, Lenovo, Advan, Ainol, dan Smartfren Andromax dengan spesifikasi yang berbeda-beda. Seluruh fitur yang terdapat pada Game Jegog Berbasis Android dapat dijalankan pada semua perangkat yang diujikan dan tidak terjadi error. Kualitas suara dan musik dari aplikasi akan lebih baik jika menggunakan speakerlearphone tambahan khsusunya untuk suara instrumen Kuntung, Pemada, dan Jegogan yang memiliki nada suara rendah.

\section{SIMPULAN}

Berdasarkan penelitian dan pengembangan aplikasi Game Jegog Berbasis Android yang telah dilakukan, maka diperoleh kesimpulan sebagai berikut.

a. Game Jegog Berbasis Android merupakan aplikasi yang mengadaptasikan Gamelan Jegog yang merupakan alat musik tradisional ke dalam sebuah game yang dijalankan pada platform Android.

b. Perancangan Game Jegog Berbasis Android telah berhasil dilakukan dengan menggunakan model fungsional berupa UML (Unified Modeling Languange) yaitu dengan menggunakan use case diagram, activity diagram, dan sequence diagram.

c. Game Jegog Berbasis Android telah berhasil diimplementasikasan sesuai dengan rancangan yang telah dibuat sebelumnya. Game Jegog Berbasis Android diimplementasikan menggunkan bahasa pemrograman Java dengan editor Eclipse versi 4.2.1 dan plug-ins ADT (Android Development Tools) serta menggunakan AndEngine sebagai library tambahan.

d. Fitur utama dari aplikasi Game Jegog Berbasis Android adalah sebuah permainan untuk memainkan Jegog sesuai dengan tabuh yang telah disediakan. Selain itu, terdapat pula fitur berlatih dimana pengguna dapat berlatih memainkan Jegog.

e. Game Jegog Berbasis Android dapat berjalan pada enam merk perangkat Android yang diujiakan dan semua kebutuhan fungsional dapat dijalankan.

\section{REFERENSI}

[1]. Widyosismoyo, Supartono. 2004. Ilmu Budaya Dasar. Bogor : Ghalia Indonesia.

[2]. Rai, I Wayan. 2001. Gong : Antologi Pemikiran. Denpasar : Bali Mangsi.

[3]. Wulandari, Agustina Dwi. 2012. Game Edukasi Sejarah Komputer Menggunakan Role Playing Game (RPG) Maker XP Sebagai Media Pembelajaran di SMP Negeri 2 Kalibawang. Jurusan Teknik Elektronika : Universitas Negeri Yogyakarta

[4]. Triadi, Dendy. 2013. Bedah Tuntas Fitur Android. Yogyakarta : Great Publisher.

[5]. Safaat H, Nazruddin.2012.Android.Bandung : Informatika.

[6]. Wismono, Andi Taru Nugroho. 2012. Cara Mudah Membuat Game di Android. Yogyakarta : ANDI

[7]. Dharwiyanti, Sri 2003. Pengantar Unified Modeling Language (UML). http://setia.staff.gunadarma.ac.id/Downloads/files/6039/ MateriSuplemenUml.pdf

[8]. Aripurnamayana, M.Irfan.2012.Rancangan dan Pembuatan Mobile Learning Berbasis Android (Studi Kasus : Pembelajaran Sejarah di SMP). Jurusan Teknik Informatika : Universitas Gunadarma 